\title{
Microstructures and grease layer of water strider and its influence on superhydrophobicity
}

Ying Gao PhD

Professor, Changchun Institute of Technology, Changchun, China Qian Xiang PhD

Professor, Changchun Institute of Technology, Changchun, China

Yi Wang PhD

Associate Professor, Changchun Institute of Technology, Changchun, China

Yuzhuo Men PhD

Professor, Changchun Institute of Technology, Changchun, China
Xiaodong Yang PhD

Professor, Jilin Engineering Normal University, Changchun, China (corresponding author: y86908051@126.com)

Qingcheng Wang PhD

Professor, Jilin Engineering Normal University, Changchun, China Zhuojuan Yang PhD

Professor, Jilin Engineering Normal University, Changchun, China

Xiaohui Geng

Changchun Institute of Technology, Changchun, China

In this paper, the microstructures of the water strider surface were observed by scanning electron microscopy. The surfaces, including wings, legs, back and abdomen, all exhibited various compound microstructures, which are the important factors influencing the superhydrophobicity with a contact angle (CA) of up to $153^{\circ}$. Furthermore, the grease of the water strider on different substrates was studied by self-assembly of the grease for $14 \mathrm{~d}$. Images of the grease indicated that the morphology and spatial orientation of the grease depend on the substrate chosen. The grease decreased the substrate wettability by approximately $30^{\circ}$ on highly ordered pyrolytic graphite and about $23^{\circ}$ on the silicon substrates. Gas chromatography combined with mass spectrometry was also used to study the chemical composition of the grease layer of water strider surface. The grease layer is composed of a mixture of aliphatic compounds, which possess hydrophobicity based on the chemical structure. Grease protects the microstructures of water strider surfaces and thus results in higher CAs and hydrophobic properties. The microstructure and the grease of the water strider jointly render the hydrophobic properties of the water strider surface.

\section{Introduction}

The world is replete with natural materials that exhibit fascinating properties tailored to specific functions. One of the most important properties of natural materials is the hydrophobicity and hydrophilicity of solid surfaces in both flora and fauna. ${ }^{1-8}$ For instance, water striders and spiders can stand effortlessly and move quickly on water due to their superior water repellency and the surface tension of water. Lotus leaves possess perfect selfcleaning thanks to their unique non-wetting properties. Superhydrophobic properties found in nature have been previously reviewed. ${ }^{9,10}$ Functional surfaces with distinct wettability have attracted much interest because of their great advantages in technical applications, such as self-cleaning windows, windshields, exterior paints for buildings and navigation of ships, utensils, roof tiles and textiles.

Land plants provide specific functional leaf surfaces in order to reduce water loss and to prevent debris adhesion. For research on land plants, a number of methods have been proposed. The leaf surfaces of land plants are covered with hydrophobic cuticles, frequently covered with wax crystals. ${ }^{11}$ These epicuticular waxes are of importance for the interaction of plants with their environment. The superhydrophobicity of leaf surfaces originates in the hierarchically arranged particles producing distinct roughness of an intrinsically hydrophobic surface and surface chemistry. ${ }^{12-15}$ Natural wax crystals have been employed in onestep production so that they serve both as the chemical element and as the roughness element. ${ }^{1}$ For example, waxes were extracted from the wheat leaf, and crystals of these waxes were grown by thermal evaporation on different surfaces. ${ }^{16,17}$ Barthlott and Neinhuis ${ }^{18}$ and Kunst and Samuels ${ }^{19}$ stated that waxes on the leaves of lotus and nasturtium resulted in hydrophobicity and surface roughness, responsible for the superhydrophobicity of these leaves. The multifunctional properties of the cuticle and waxes have been previously summarized. ${ }^{20,21}$

Certain insect species such as butterflies, ${ }^{22,23}$ water striders, ${ }^{24,25}$ lacewings, ${ }^{26,27}$ termites, ${ }^{28}$ craneflies $^{29}$ and cicadas ${ }^{30-33}$ present wings or legs which are hydrophobic or superhydrophobic. The surfaces of an insect's integument provide a large diversity of functions, which can inspire biomimetic surfaces and materials. Some typical characteristics such as the morphology, structures and material properties of animal multifunctional surfaces have been reviewed. ${ }^{34}$ The interrelationship between the construction of attachment systems on insects and their function has been outlined. ${ }^{35}$

Among insects, adult water striders show superior water repellency. In previous theoretical analyses, the legs of the water strider are usually treated as rigid beams and a tremendously deep 
dimple and a large supporting force can be achieved when the leg descends into water. Some studies revealed that the supporting force of each leg can reach up to 15 times the total body weight. ${ }^{24}$ Feng et $a l^{36}$ investigated the water repellency mechanism of water strider legs. They considered that the uniquely hierarchically arranged structures covering the legs plays a crucial role, which ensures that the legs can make tremendous dimples without piercing the water surface. Ji et al. ${ }^{37}$ analyzed the effect of the flexibility of water strider legs on their water-repellent ability, both theoretically and experimentally. They discovered that the leg may undergo a large deformation and assume different geometric configurations. Goodwyn et al. ${ }^{38}$ thought that the density and length of the setae was nearly the same as that on the body and legs of adults. The setal coverage on adult water strider's body resulted in the hydrophobic properties. ${ }^{39}$ Although the influence of the legs on the superhydrophobicity and the various behaviors of water strider have been widely studied, the effects of the microstructures and the grease layer of water strider surfaces on wettability have received little attention.

In this paper, adult water striders were selected to explore wettability properties. By comparing the effects of the microstructure and the chemical composition of grease on water strider surfaces on hydrophobicity, it was found that the superhydrophobicity of water striders is attributed to their unusual microstructures in combination with chemical composition. The use of water strider grease layer for hydrophobization and nanostructuring of artificial surfaces provides a reproducible route.

\section{Experimental section}

\subsection{Ethics statement}

No specific permits were required for the described field studies, and the localities where water striders were collected are not privately owned or protected in any way.

\subsection{Water strider sample}

Adult water striders Aquarlus elongatus Uhler (Heteroptera, Gerridae) were obtained from the Ren Gong Lake of Northeast Normal University in Jilin Province of China in summer (geographic coordinates: $43 \cdot 8582575334^{\circ}$ north, $125 \cdot 325587812^{\circ}$ east). The water strider specimens' weight was about $20 \mathrm{mg}(n=$ 20; males and females pooled together). All the samples were taken from a live water strider just before the experiments in order to maintain freshness and simulate real performance.

The wettability of the water strider's body surfaces was estimated by contact angle (CA) measurements in this study. However, it was difficult to measure directly CAs on water strider body surfaces with superior water repellency due to their small surface area and specific shape. In fact, droplets could not adhere to a single leg and a back with curved surface. In order to measure the CA on a water strider's leg, specially prepared specimens of water striders were used in this study. Seven legs of water striders were collected and arranged parallel to each other on a flat plane.
Droplets were applied on top of the specimens, and the CAs were automatically determined by applying the sessile drop and ellipse fitting method.

\subsection{Water strider grease extraction}

Superficial grease can be dissolved and removed from the surfaces of a water strider by using a solvent. The chemical properties of a solvent along with the contact time between solvent and water striders were found to represent crucial parameters. Alcohol, acetone, cyclohexane, ethyl acetate and chloroform were used for the extraction of water strider superficial grease. In this study, chloroform was selected as the optimized extraction solvent because it gives reproducible results. ${ }^{17}$

In this study, the effect of the extraction time on the microstructures of the water strider surface was investigated by increasing the extraction time in a time range from 2 to $8 \mathrm{~s}$. No favorable microstructures on the water strider surface were obtained with increasing the extraction time in this study. Some pieces of substance were found on the water strider surfaces. Also, the microstructures of water strider were affected. Both the grease and other ingredients can be dissolved by using a long extraction time. Although the grease cannot be washed off completely within $2 \mathrm{~s}$, a fine hierarchical microstructure of water strider surface can be kept. Thus, as similarly done in wax extraction from plants, a short immersion time was chosen for the extraction of grease compounds. ${ }^{40}$ Water striders were dipped in chloroform for $2 \mathrm{~s}$. Then, the extracts were combined and filtered through a $0.22 \mu \mathrm{m}$ cellulose acetate filter membrane produced by Shanghai Xinya Purification Apparatus Factory (Shanghai, China). Solutions of the grease were stored at $4^{\circ} \mathrm{C}$ in a refrigerator.

\subsection{Substrates}

Freshly cleaved highly ordered pyrolytic graphite (HOPG) was used for studying the grease accumulation processes. Also, silicon wafers were used as the substrates for grease accumulation. The silicon wafers were cleaned ultrasonically in ethanol for $3 \mathrm{~min}$. They were dried in a desiccator at ambient temperature before applying the grease solutions.

\subsection{Chemical analysis (gas chromatography)}

The extracted grease was analyzed by gas chromatography-mass spectrometry (GC-MS) (6890N-5975, Agilent, USA) with oncolumn injection. The injector was a standard split/splitless injector. MS detection was in electron impact mode. One microliter of the samples was injected into the chromatograph. Quantification of the single compounds was done by referring to an internal standard, which was added to the grease samples directly before GC analysis. Detection was performed in single ion monitoring mode.

\subsection{Scanning electron microscopy}

A scanning electron microscope (model S-3400N, Hitachi, Tokyo, Japan) was used to characterize the microstructures of the water 
strider surface and the morphology of the grease on technical surfaces. Specimens were mounted on aluminum stubs with double-sided adhesive tape and coated with an approximately $25-30 \mathrm{~nm}$ thick gold layer. Alive water striders were used to investigate the morphology of the body surface. Additionally, $10 \mu \mathrm{l}$ large droplets of the grease-chloroform solutions were placed on the substrates and the specimens were stored in a desiccator. A statistical analysis of the morphology of the grease accumulation on technical surfaces was performed after $14 \mathrm{~d}$.

\subsection{Contact angle measurement}

The wetting properties of the water strider surface were identified using the CA measurement device DSA100 combined with the software Drop Shape Analysis 100 system (DataPhysics Instruments $\mathrm{GmbH}$, Filderstadt, Germany). In addition, the wettability of the different substrates before and after covering it with the grease layer was measured through CA measurement. Five microliters of demineralized water was applied on top of the samples, and the CAs were automatically determined by applying the sessile drop and ellipse fitting method. A total of five measurements at different positions were carried out and pooled to evaluate an average CA.

\section{Results and discussion}

The microstructures and the grease layer of water strider surfaces and their influence on superhydrophobicity are analyzed in the following.

\subsection{Relationship between microstructures of water strider integument surfaces and hydrophobicity \\ 3.1.1 Microstructural observation of the water strider surface}

The surface microstructures of the water strider were observed by scanning electron microscopy (SEM). SEM images showed that the surfaces of water strider wings, legs, back and abdomen all exhibited various microstructures, such as spherical chains, setae and burr clusters, which are the important factors that influence the wetting properties of water strider surface. Rougher surfaces tended to present a stronger hydrophobicity.

Among the water strider surfaces, the wings possess a unique microstructure as seen in Figure 1. The wing surface shows a combination of different-length chains and balls, which look like several tadpoles gathering together and moving in the same direction. The head and tail connect the string shape. The wing surface bears tapered setae. The SEM image confirms that the length of the setae was about $2 \mu \mathrm{m}$, while the diameter of the setae head was approximately $600 \mathrm{~nm}$. The distance between the rows of setae was about $2 \mu \mathrm{m}$.

Figure 2 shows the microstructures of the water strider legs, which are covered with bristles, setae and microtrichia. That finding is in accordance with previous reports of Goodwyn et al. ${ }^{41}$ The setae are arranged regularly in the same direction according to the uniform distribution. Two setae possess different diameters and similar lengths. Bristle length was about $50 \mu \mathrm{m}$, and the distances between them were about $10 \mu \mathrm{m}$. The diameter of a small seta was approximately $2 \mu \mathrm{m}$. The diameter of bristles was ten times larger than that of setae. In addition, the surfaces of the bristles showed many nanoscale pits and grooves. The water strider legs present a compound three-dimensional (3D) arrangement of microstructures.

Figure 3 illustrates the typical magnified image of the back of the water strider, wherein a periodic array of microtrichia with individual $2 \mu \mathrm{m}$ average diameter and $50 \mu \mathrm{m}$ average length. The distance between microtrichia was about $10 \mu \mathrm{m}$.

Similar to the legs, the abdomen of water striders shows hybridization of 3D microstructures, which has a uniform distribution in the whole region as shown in Figure 4. The micropatterns are composed of the clusters of upper long setae and the low filiform microtrichia. The clusters of setae with $2 \mu \mathrm{m}$ average diameter locate within the low filiform microtrichia, and the upper setae are about $50 \mu \mathrm{m}$ longer than the filiform

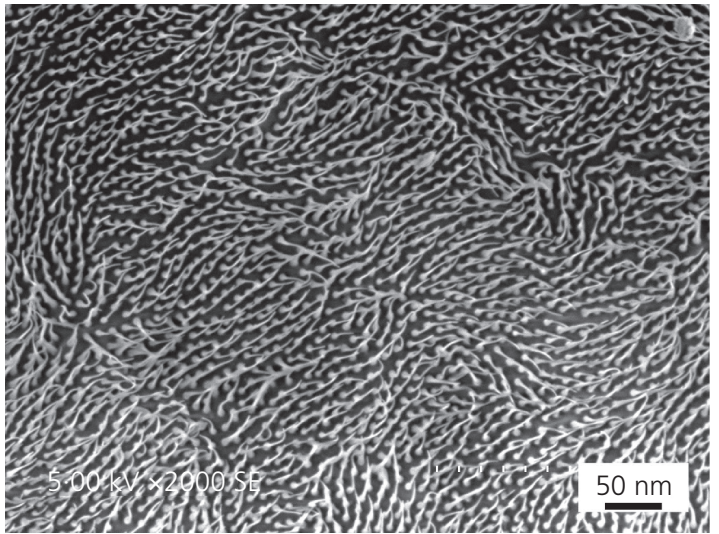

(a)

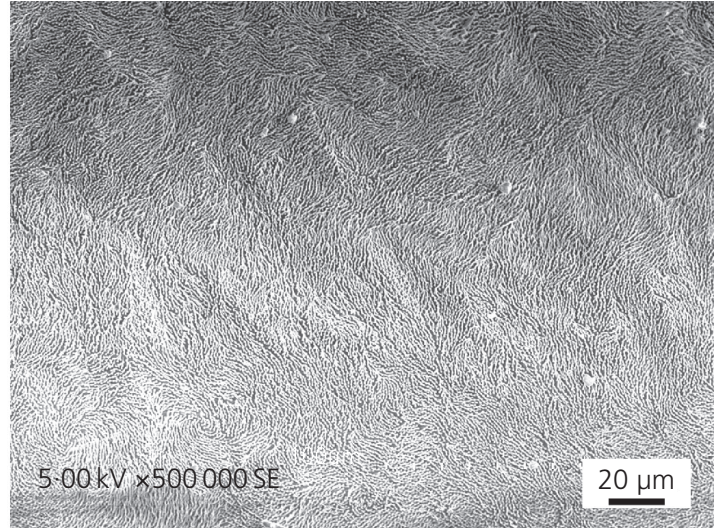

(b)

Figure 1. (a, b) SEM images of microstructures (setae) on the water strider wing. The scale bar is $50 \mathrm{~nm}$ in (a) and $20 \mu \mathrm{m}$ in (b) 
Bioinspired, Biomimetic and Nanobiomaterials Volume 7 Issue BBN1
Microstructures and grease layer of water strider and its influence on

superhydrophobicity

Gao, Xiang, Wang et al.

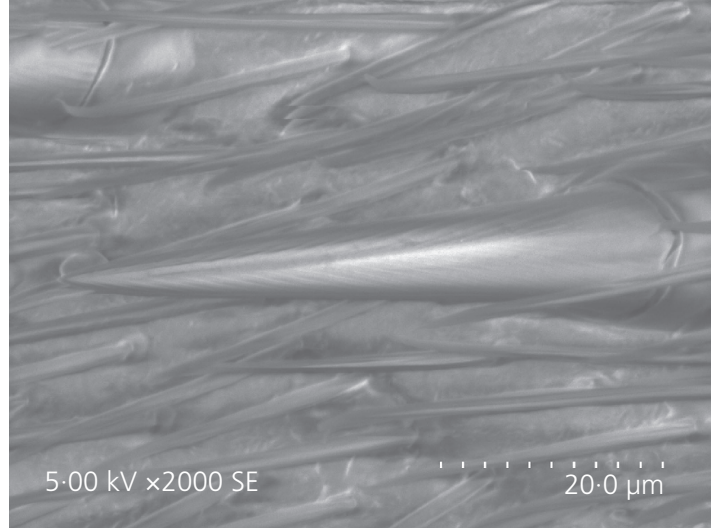

(a)

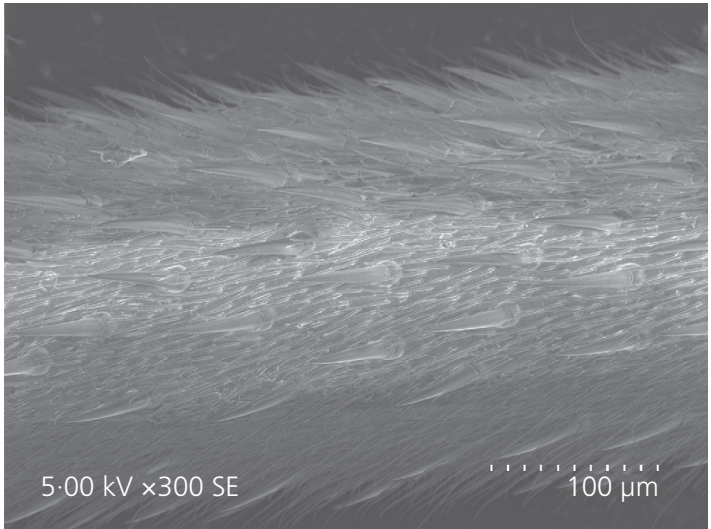

(b)

Figure 2. (a, b) SEM images of microstructures of the water strider leg. Bristles, setae and microtrichia are visible. The scale bar is $20 \mu \mathrm{m}$ in (a) and $100 \mu \mathrm{m}$ in (b)

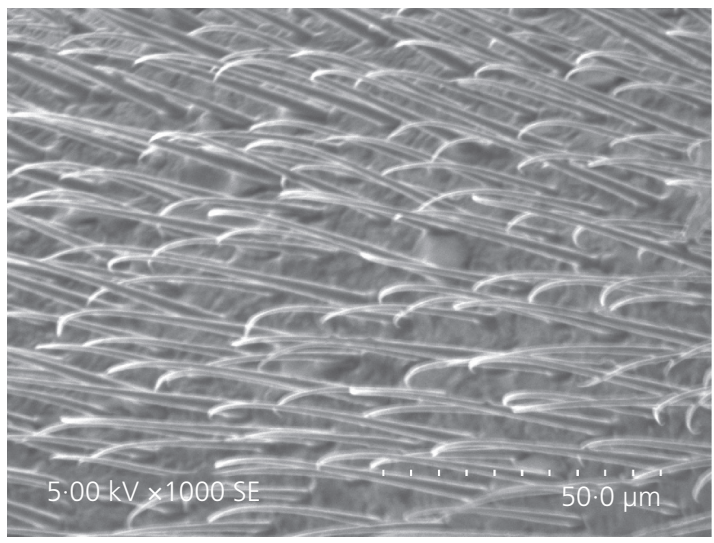

(a)

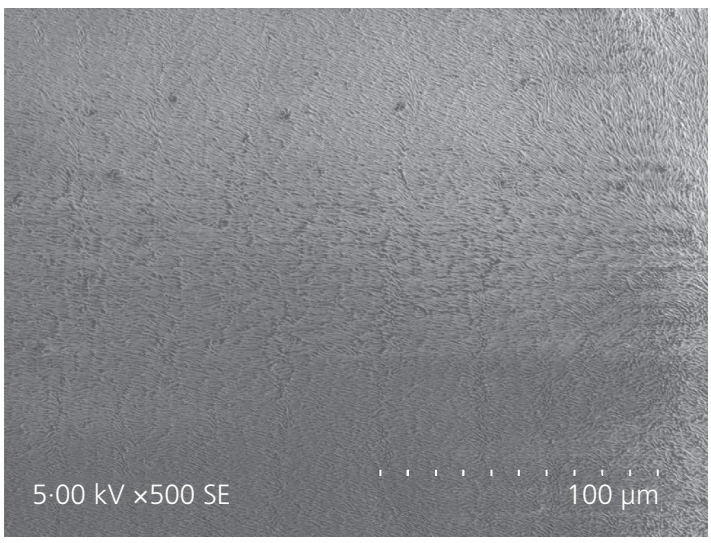

(b)

Figure 3. (a, b) SEM images of microstructures (microtrichia) of the water strider back. Scale bar is $50 \mu \mathrm{m}$ in (a) and $100 \mu \mathrm{m}$ in (b)

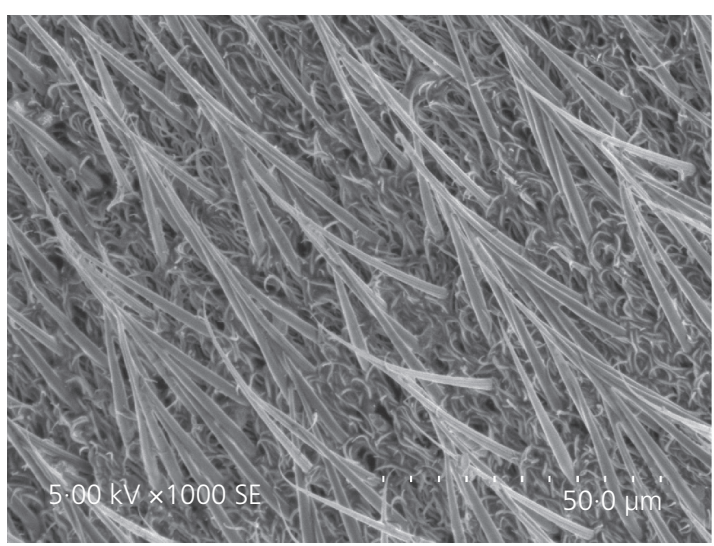

(a)

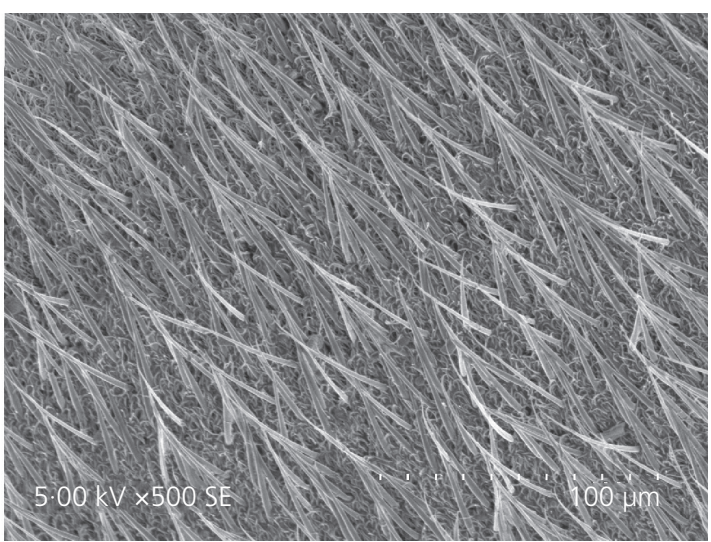

(b)

Figure 4. (a, b) SEM images of microstructures of the water strider abdomen. The scale bar is $50 \mu \mathrm{m}$ in (a) and $100 \mu \mathrm{m}$ in (b) 
Microstructures and grease layer of water strider and its influence on superhydrophobicity Gao, Xiang, Wang et al. microtrichia. The filiform microtrichia are small and dense. Their width is up to $600 \mathrm{~nm}$.

\subsubsection{Effect of integumental microstructures on superhydrophobicity of water strider body surfaces}

A water strider surface appears dark gray in air. However, its body is surrounded by sparkling silvery light when the water strider sinks into water. A large supporting force can be achieved in water due to the presence of sparkling air layer. The water strider surfaces, such as the back, abdomen and wings, were used directly for the determination of CAs.

When the water droplet CA on a surface is $\angle 90^{\circ}$, water has a tendency to spread over the surface; the surface is termed 'hydrophilic'. In contrast, if the water droplet CA is $>90^{\circ}$, and the surface thus repels spreading of water, the surface is termed 'hydrophobic'. If the water CA on a hydrophobic surface is $>150^{\circ}$, and the droplet thus takes a spherical shape on the solid, the surface is often termed 'superhydrophobic'. The water strider integument exhibited superhydrophobicity with a CA of up to $153^{\circ}$. Among the water strider body parts, the back and the wings achieved the smallest CAs (Figures 5(c) and 5(d)). The legs and abdomens showed slightly larger CAs of $160^{\circ}$ (Figure 5(a)) and $158^{\circ}$ (Figure 5(b)), respectively. Five measurements at different positions were carried out and pooled to evaluate an average CA.

Various parts of water strider surfaces possess roughness at both nanometer and micrometer scales and tend to show a perfect hydrophobic property. Compared with the wings and the back, the legs and the abdomen of the water strider show larger CAs due to their hierarchically arranged microstructures as shown in Figures $1-4$. Thus, the hierarchically arranged microstructures of water strider surfaces have very important influence on superhydrophobicity.

\subsection{Relationship between chemistry and wettability}

The cuticle of most insects is covered by lipoid substances consisting chiefly of hydrocarbons and esters, which are solid waxes forming a greasy layer on the epicuticle. ${ }^{42}$ In order to study the relationship between the chemistry and the wettability of that greasy layer, the surface lipoid substances of the integument were extracted and analyzed.

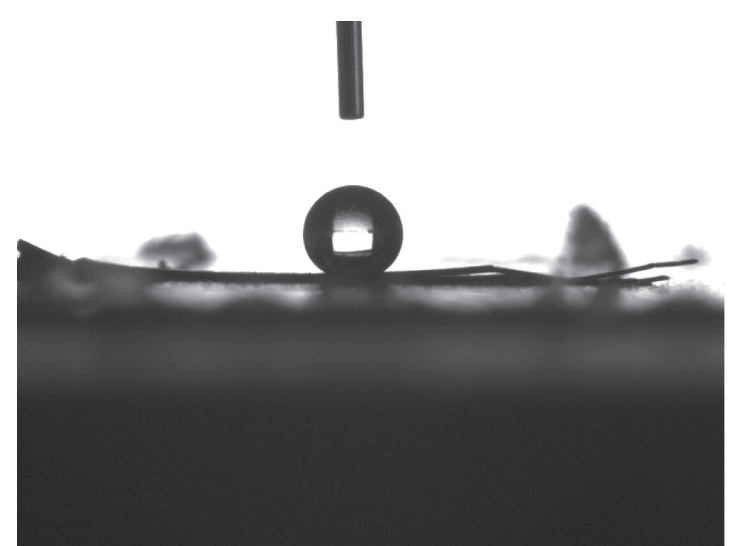

(a)

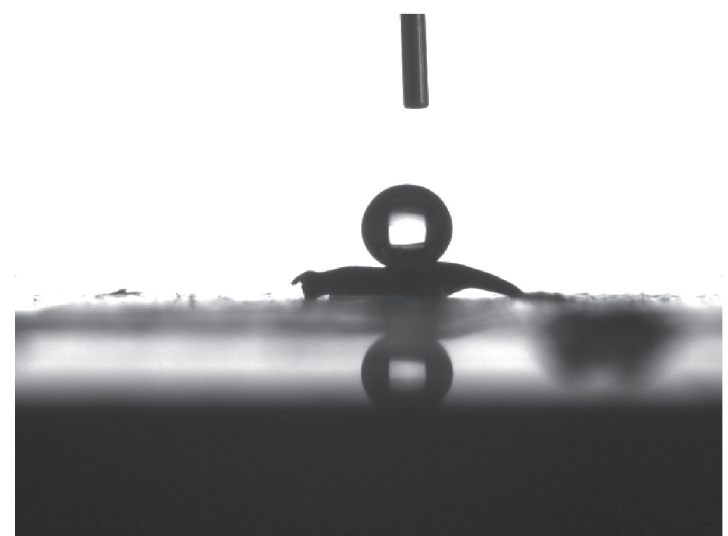

(c)

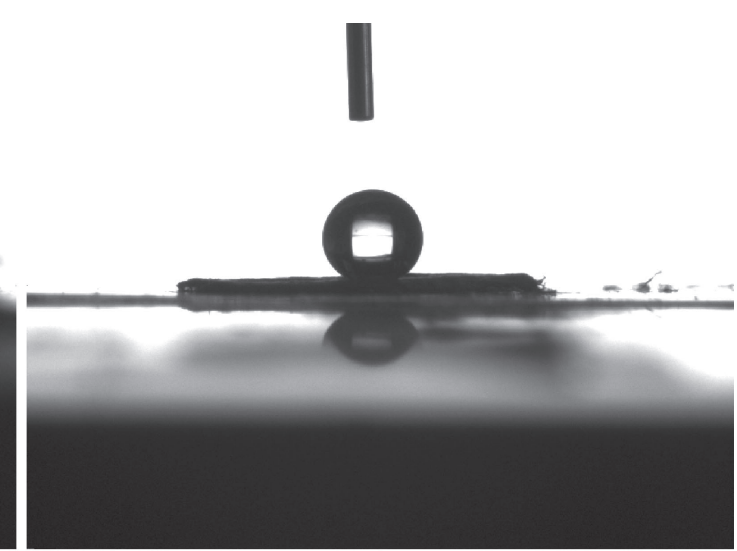

(b)

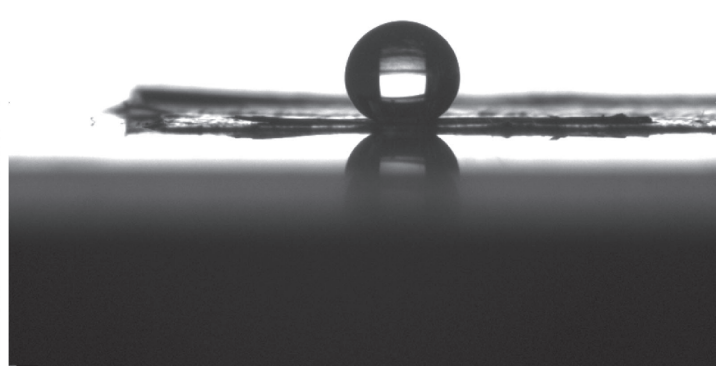

(d)

Figure 5. CAs of water on water striders body surface: (a) CA of water on water strider's leg; (b) CA of water on water strider's abdomen (ventral); (c) CA of water on water strider's back; (d) CA of water on wings of water strider 
Table 1. Composition of water strider lipoid superficial grease

\begin{tabular}{lrrr} 
Chain length & $\begin{array}{c}\text { Alkanes: } \\
\text { wt } \%\end{array}$ & $\begin{array}{c}\text { Alcohols: } \\
\text { wt\% }\end{array}$ & $\begin{array}{c}\text { Fatty acids: } \\
\text { wt } \%\end{array}$ \\
15 & $1 \cdot 2$ & & \\
16 & $0 \cdot 8$ & & \\
17 & $2 \cdot 8$ & $4 \cdot 6$ & \\
18 & $1 \cdot 5$ & & \\
19 & $1 \cdot 0$ & & \\
20 & $1 \cdot 3$ & & \\
21 & $2 \cdot 3$ & \\
22 & $1 \cdot 8$ & \\
23 & $2 \cdot 7$ & \\
27 & $4 \cdot 8$ & \\
28 & $3 \cdot 7$ & \\
29 & $25 \cdot 5$ & & \\
34 & $8 \cdot 2$ & & \\
35 & $6 \cdot 0$ & & \\
36 & $6 \cdot 1$ & & \\
44 & $13 \cdot 4$ & & \\
& & & \\
\hline
\end{tabular}

Mean values are given for the homologous composition (\% of the fraction) not identified $4.2 \%$

\subsubsection{Chemical composition of water strider epicuticular grease}

The extracted substances were analyzed by GC-MS. As shown in Table 1, the grease were principally composed of aliphatic hydrocarbons with various chain lengths $(83 \cdot 1 \mathrm{wt} \%)$. Different aliphatic acids $(8 \cdot 1 \mathrm{wt} \%)$ and aliphatic alcohols $(4 \cdot 6 \mathrm{wt} \%)$ were found as well. In total, $95.8 \mathrm{wt} \%$ of the detected peaks were identified, which include all major peaks in the GC-MS spectrum.

\subsubsection{Relationship between chemistry and wettability}

The cuticle of insects is usually covered by lipoids consisting of hydrocarbons and esters, which are waxes forming a thin greasy layer on the epicuticle. The waterproofing abilities of the cuticle depend on the physical properties of grease, which depend in turn on their chemical composition. ${ }^{43}$

In this study, hydrocarbons with long chains ranging from 15 to 44 carbons are the predominant constituents in the water strider grease. Generally, hydrocarbons with long chains possess good hydrophobicity based on their chemical structure. Chemistry is an important factor that affects the hydrophobicity of the water strider surface, and it should be partly responsible for the superhydrophobicity of the water strider.

\subsection{Influence of water strider grease on wetting properties}

For further discussion on the effect of water strider grease on wetting properties, the grease on different substrates was investigated.

\subsubsection{Grease accumulation on technical surfaces}

Technical surfaces, such as HOPG and silicon, were used for studying the accumulation processes of the water strider grease. In grease studies, the grease components were dissolved in chloroform and accumulated after evaporation under ambient temperature and $50 \%$ relative humidity.

Therefore, $10 \mu 1$ droplets of the grease-chloroform solutions were placed on the substrates and stored in a desiccator. The grease coverage over the substrates was homogeneous, and the droplets covered an area of about $1.0 \mathrm{~cm}^{2}$. The bulk of the chloroform evaporated within about $1 \mathrm{~min}$, and grease formation was started immediately. Over a period of $14 \mathrm{~d}$, different grease morphologies arose on the substrates by self-assembly of the grease molecules.

\subsubsection{Appearance of grease on technical surfaces}

By self-assembly of dissolved grease components on substrates for $14 \mathrm{~d}$, well-defined surface structures with grease morphologies were created. SEM was used to characterize the morphology and spatial distribution of the grease covering the substrates.

In this study, great differences were found in the morphology and the spatial distribution of the grease on two substrates. On silicon substrates, the grease preferably formed thin crusts; the grease looked like snowflakes pasted on the substrate as shown in Figure 6(a). Although flat growing grease is visible, the increase in grease height is not obvious.

Figure 6(b) shows an SEM image on HOPG substrate obtained after the application of the water strider grease solution. The grease formed a network structure, which is made of many tubers with about $2 \mu \mathrm{m}$ length and approximately $700 \mathrm{~nm}$ width. The morphology and spatial orientation of the grease were different for the HOPG and the silicon substrates. SEM images indicated that the morphology of grease depend on the substrate chosen. The possible reason is that the polarity of the substrate has a crucial influence on the grease accumulation due to molecular interactions between the grease molecules and the substrate, resulting in the spatial orientation of the grease on the substrate during evaporation. On non-polar substrate surfaces, the weak van der Waals forces lead to grease nucleation directly on the substrate, and grease molecules grow randomly orientated to the substrate.

\subsubsection{Wettability of grease on technical substrates}

The hydrophobicity of the grease was determined at $14 \mathrm{~d}$ after applying the grease solution to the technical surfaces, by measuring the CA. The CA of HOPG with the grease increased from $72^{\circ}$ (standard deviation $=3^{\circ}, n=5$ ) to $102^{\circ}$ (standard deviation $=5^{\circ}, n=5$ ). The hydrophobicity of the silicon surfaces covered with the grease increased from $82^{\circ}$ (standard deviation $4^{\circ}, n=5$ ) to $105^{\circ}$ (standard deviation $=6^{\circ}, n=5$ ). The grease improved the hydrophobicity of technical surfaces. The grease led to a better understanding of the correlation between the grease and hydrophobicity.

\subsection{Treated water strider surface}

On the rough superhydrophobic surface, there are two possible wetting states: Wenzel state and Cassie state. ${ }^{13,44}$ If the water droplets stay in the Wenzel state, water can penetrate the grooves 


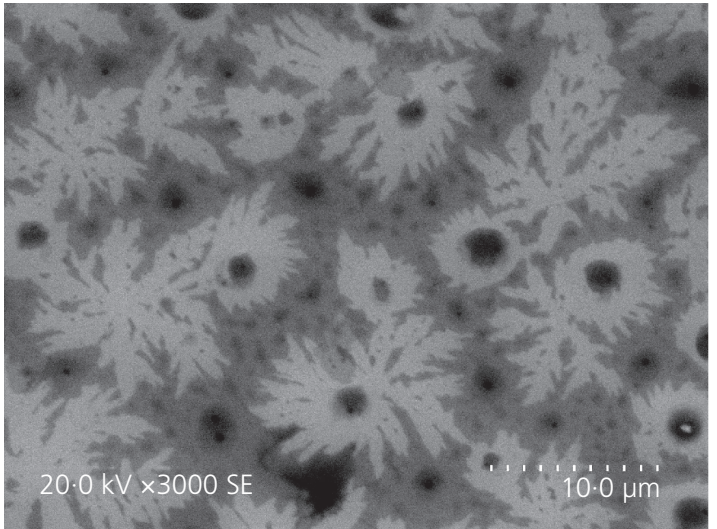

(a)

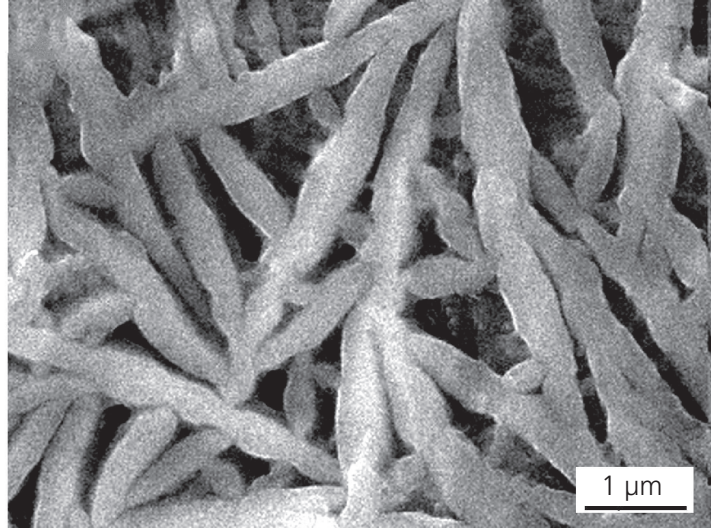

(b)

Figure 6. Images of the water strider grease on the (a) silicon surface and (b) HOPG surface

due to the 3D capillary effect and the water droplets do not slide easily on the interfacial surface. In the Cassie state, the water droplets cannot penetrate the grooves. Air is trapped in the grooves, and the remaining water droplets slide easily.

The water strider surface is surrounded by sparkling silvery light when the water strider sinks into water. The water strider surfaces, including the wings, legs, back and abdomen, all exhibited various compound hierarchical microstructures, such as spherical chains, setae and burr clusters. Water droplets could not penetrate into the grooves of the water strider surface because there exists trapped air. A large supporting force for water strider can be achieved in water due to the presence of sparkling air layer. The superhydrophobic behavior of the water strider surfaces can be explained theoretically in terms of the Cassie model.

In general, the water strider surfaces have a fine hierarchical structure coated with a thin greasy, lipoid layer, and the water strider exhibits superhydrophobic property. After the chloroform treatment, the grease of water striders was washed off with chloroform. Some pieces of substance were found on the water strider surfaces, and the microstructures of water strider were affected as shown in Figures 7(a) and 7(b). The CAs on water strider surfaces were all reduced. A difference of about $20^{\circ}$ between the untreated and treated water strider surfaces was found. This kind of treated water strider surface was hydrophobic. A possible reason is that there was a reversible transition on the water strider surface from the Cassie model (superhydrophobicity) to the Wenzel model (hydrophobicity) because some of the grease was dissolved and removed from the water strider surface.

Grease protected the microstructures of water strider surfaces and thus resulted in large CAs and hydrophobic properties. The grease was also responsible for the superhydrophobicity of water strider surfaces. The microstructure and grease of the water strider jointly determined the hydrophobic properties of the water strider surface.

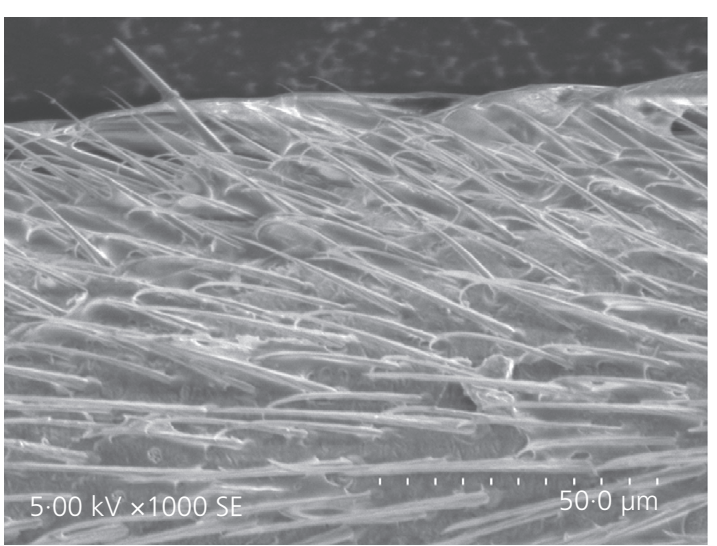

(a)

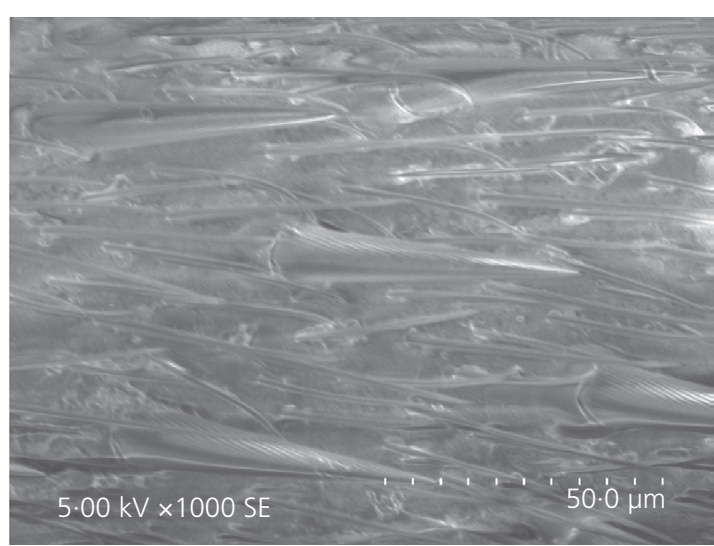

(b)

Figure 7. SEM images of water strider's (a) back and (b) leg after rinsing with chloroform 
Bioinspired, Biomimetic and Nanobiomaterials Volume 7 Issue BBN1
Microstructures and grease layer of water strider and its influence on superhydrophobicity Gao, Xiang, Wang et al.

\section{Concluding remarks}

The surfaces of the wings, legs, back and abdomen of water striders exhibited various compound microstructures (bristles, setae, microtrichia), which are the important factors influencing superhydrophobicity. The grease layer is composed of a mixture of aliphatic compounds. The grease of the water striders increased the hydrophobicity of the test substrate by self-assembly for $14 \mathrm{~d}$. Images indicated that the morphology and spatial orientation of the grease depend on the substrate chosen. An amorphous superficial wax-oily layer (grease) can protect the microstructures of water strider surfaces and thus results in a high CA. After the chloroform treatment, the CAs on water strider surfaces were all reduced. A difference of about $20^{\circ}$ between the untreated and treated water strider surfaces was found. By comparing the effects of the microstructure and the grease chemical composition of water strider surfaces on hydrophobicity, it was found that the microstructure and grease of the water strider jointly determine the hydrophobic properties of the water strider surface. However, the authors' approach has to be considered carefully and critically, because non-common CA measurements were applied for the rod-shaped legs, and the control samples were missed in the experiments. These aspects will be addressed in future studies to confirm the authors' present findings.

\section{Acknowledgements}

This project was supported by National Natural Science Foundation of China (numbers 51275055 and 21427811), the Natural Science Foundation of Jilin Province, China (number 20140101153JC) and the Scientific and Technological Developing Scheme of Jilin Province (number 2015287).

\section{REFERENCES}

1. Sasha P and Boaz P (2012) Self-assembling. Advanced Functional Materials 22(4): 745-750.

2. Neinhuis C and Barthlott W (1997) Characterization and distribution of water-repellent, self-cleaning plant surfaces. Annals of Botany 79: 667-677.

3. Neinhuis C and Barthlott W (1998) Seasonal changes of leaf surface contamination in beech, oak and ginkgo in relation to leaf micromorphology and wettability. New Phytologist 138(1): 91-98.

4. Bhushan B and Jung YC (2006) Micro- and nanoscale characterization of hydrophobic and hydrophilic leaf surfaces. Nanotechnology 17(11): 2758-2772.

5. Ren LQ, Wang SJ, Tian XM et al. (2007) Non-smooth morphologies of typical plant leaf surfaces and their anti-adhesion effects. Journal of Bionic Engineering 4(1): 33-40.

6. Koch K, Bhushan B and Barthlott W (2008) Diversity of structure, morphology and wetting of plant surfaces. Soft Matter 4: 1943-1963.

7. Koch K, Bohn HF and Barthlott W (2009) Hierarchically sculptured plant surfaces and superhydrophobicity. Langmuir 25(24): 14116-14120.

8. Barthlott W, Schimmel T, Wiersch S et al. (2010) The Salvinia paradox: superhydrophobic surfaces with hydrophilic pins for air retention under water. Advanced Materials 22(21): 2325-2328.

9. Darmanin T and Guittard F (2015) Superhydrophobic and superoleophobic properties in nature. Materials Today 18(5): 273-285.

10. Webb HK, Crawford RJ and Ivanova EP (2014) Wettability of natural superhydrophobic surfaces. Advances in Colloid and Interface Science 210: $58-64$.

11. Jeffree CE (2007) The Fine Structure of the Plant Cuticle. Blackwell, Oxford, UK.
12. Wenzel RN (1936) Resistance of solid surfaces to wetting by water. Industrial \& Engineering Chemistry Research 28(8): 988-994.

13. Cassie ABD and Baxter S (1944) Wettability of porous surfaces. Transactions of the Faraday Society 40: 546-551.

14. Bico J, Marzolin C and Quere D (1999) Pearl drops. Europhysics Letters 47(2): 220-226.

15. Oner D and McCarthy TJ (2000) Ultrahydrophobic surfaces: effects of topography length scales on wettability. Langmuir 16(20): 7777-7782.

16. Koch K, Barthlott W, Koch S et al. (2006) Structural analysis of wheat wax (Triticum aestivum, c.v. 'Naturastar' L.): from the molecular level to three dimensional crystals. Planta 223: 258-270.

17. Niemietz A, Wandelt K, Barthlott W and Koch K (2009) Thermal evaporation of multi-component waxes and thermally activated formation of nanotubules for superhydrophobic surfaces. Progress in Organic Coatings 66(3): 221-227.

18. Barthlott $W$ and Neinhuis C (1997) Purity of the sacred lotus, or escape from contamination in biological surfaces. Planta 202(1): 1-8.

19. Kunst $L$ and Samuels AL (2003) Biosynthesis and secretion of plant cuticular wax. Progress in Lipid Research 42: 51-80.

20. Bargel H, Koch K, Cerman Z and Neinhuis C (2006) Evans Review No. 3: structure-function relationships of the plant cuticle and cuticular waxes - a smart material? Functional Plant Biology 33(10): 893-910.

21. Koch K, Bhushan B and Barthlott W (2009) Multifunctional surface structures of plants: an inspiration for biomimetics. Progress in Materials Science 54(2): 137-178.

22. Fang Y, Sun G, Wang TQ, Cong Q and Ren LQ (2007) Hydrophobicity mechanism of non-smooth pattern on surface of butterfly wing. Chinese Science Bulletin 52(5): 354-357.

23. Zheng YM, Gao XF and Jiang L (2007) Directional adhesion of superhydrophobic butterfly wings. Soft Matter 3: 178-182.

24. Gao XF and Jiang L (2004) Biophysics: water-repellent legs of water striders. Nature 432(11): 36.

25. Watson GS and Cribb BW (2010) Experimental determination of the efficiency of nanostructuring on non-wetting legs of the water strider. Acta Biomaterialia 6(10): 4060-4064.

26. Watson GS, Cribb BW and Watson JA (2010) The role of micro/nano channel structuring in repelling water on cuticle arrays of the lacewing. Journal of Structural Biology 171(1): 44-51.

27. Watson JA, Cribb BW, Hu HM and Watson GS (2011) A dual layer hair array of the brown lacewing: repelling water at different length scales. Biophysical Journal 100(4): 1149-1155.

28. Watson GS, Cribb BW and Watson JA (2010) How micro/ nanoarchitecture facilitates anti-wetting: an elegant hierarchical design on the termite wing. ACS Nano 4(1): 129-136.

29. Hu HM, Watson GS, Cribb BW and Watson JA (2011) Non-wetting wings and legs of the cranefly aided by fine structures of the cuticle. Journal of Experimental Biology 214: 915-920.

30. Watson GS, Myhra S, Cribb BW and Watson JA (2008) Putative functions and functional efficiency of ordered cuticular nanoarrays on insect wings. Biophysical Journal 94(8): 3352-3360.

31. Sun MX, Watson GS, Zheng YM, Watson JA and Liang AP (2009) Wetting properties on nanostructured surfaces of cicada wings. Journal of Experimental Biology 212: 3148-3155.

32. Sun MX, Liang AP, Zheng YM, Watson GS and Watson JA (2011) A study of the antireflection efficiency of natural nano-arrays of varying sizes. Bioinspiration \& Biomimetics 6(2): 026003.

33. Sun M, Liang A, Watson GS, Watson JA and Zheng Y (2012) Influence of cuticle nanostructuring on the wetting behaviour/states on cicada wings. PLoS One 7(4): e35056.

34. Han ZW, Mu ZZ, Yin W et al. (2016) Biomimetic multifunctional surfaces inspired from animals. Advances in Colloid and Interface Science 234(8): 27-50.

35. Gorb S (2001) Attachment Devices of Insect Cuticle. Springer, Dordrecht, the Netherlands. 
Bioinspired, Biomimetic and Nanobiomaterials Volume 7 Issue BBN1
Microstructures and grease layer of water strider and its influence on superhydrophobicity Gao, Xiang, Wang et al.
36. Feng XQ, Gao XF, Wu ZN, Jiang L and Zheng QS (2007) Superior water repellency of water strider legs with hierarchical structures: experiments and analysis. Langmuir 23(9): 4892-4896.

37. Ji XY, Wang JW and Feng XQ (2012) Role of flexibility in the water repellency of water strider legs: theory and experiment. Physical Review E 85(2): 021607.

38. Goodwyn PJP, Voigt D and Fujisaki K (2008) Skating and diving: changes in functional morphology of the setal and microtrichial cover during ontogenesis in Aquarius paludum Fabricius (Heteroptera, Gerridae). Journal of Morphology 269(6): 734-744.

39. Goodwyn PP, Souza ED, Fujisaki K and Gorb S (2008) Moulding technique demonstrates the contribution of surface geometry to the super-hydrophobic properties of the surface of a water strider. Acta Biomaterialia 4(3): 766-770.
40. Koch K, Dommisse A and Barthlott W (2006) Chemistry and crystal growth of plant wax tubules of lotus (Nelumbo nucifera) and nasturtium (Tropaeolum majus) leaves on technical substrates. Crystal Growth \& Design 6(11): 2571-2578.

41. Goodwyn PP, Wang J, Wang Z et al. (2008) An accurate method to directly measure water strider's stroke force on the water (Aquarius paludum: Heteroptera: Gerridae). Central European Journal of Biology 3(3): 299-305.

42. Pal R (1951) The wetting of insect cuticle. Bulletin of Entomological Research 51(1): 121-139.

43. Gibbs AG (1998) Water-proofing properties of cuticular lipids. Integrative \& Comparative Biology 38(3): 471-482.

44. Wenzel RN (1936) Resistance of solid surfaces to wetting by water. Industrial and Engineering Chemistry 28(8): 988-994.

\section{How can you contribute?}

To discuss this paper, please submit up to 500 words to the journal office at journals@ice.org.uk. Your contribution will be forwarded to the author(s) for a reply and, if considered appropriate by the editor-in-chief, it will be published as a discussion in a future issue of the journal.

ICE Science journals rely entirely on contributions from the field of materials science and engineering. Information about how to submit your paper online is available at www.icevirtuallibrary.com/page/authors, where you will also find detailed author guidelines. 